\title{
Spatiotemporal changes in the bud-burst date of herbaceous plants in Inner Mongolia grassland
}

\author{
TAO Zexing ${ }^{1}$, 'DAI Junhu' ${ }^{1}$, WANG Huanjiong ${ }^{1}$, HUANG Wenjie ${ }^{1,2,3}$, \\ GE Quansheng ${ }^{1}$ \\ 1. Key Laboratory of Land Surface Pattern and Simulation, Institute of Geographic Sciences and Natural Re- \\ sources Research, CAS, Beijing 100101, China; \\ 2. University of Chinese Academy of Sciences, Beijing 100049, China; \\ 3. College of Life Sciences, Chifeng University, Chifeng 024000, Inner Mongolia, China
}

\begin{abstract}
Phenological modeling is not only important for the projection of future changes of certain phenophases but also crucial for systematically studying the spatiotemporal patterns of plant phenology. Based on ground phenological observations, we used two existing temperature-based models and 12 modified models with consideration of precipitation or soil moisture to simulate the bud-burst date (BBD) of four common herbaceous plants-Xanthium sibiricum, Plantago asiatica, Iris lactea and Taraxacum mongolicum-in temperate grasslands in Inner Mongolia. The results showed that (1) increase in temperature promoted the BBD of all species. However, effects of precipitation and soil moisture on BBD varied among species. (2) The modified models predicted the BBD of herbaceous plants with $R^{2}$ ranging from 0.17 to 0.41 and $R M S E$ ranging from 9.03 to 11.97 days, better than classical thermal models. (3) The spatiotemporal pattern of BBD during 1980-2015 showed that species with later BBD, e.g. X. sibiricum (mean: day of year 135.30) exhibited an evidently larger spatial difference in BBD (standard deviation: 13.88 days) than the other species. Our findings suggest that influences of temperature and water conditions need to be considered simultaneously in predicting the phenological response of herbaceous plants to climate change.
\end{abstract}

Keywords: phenological model; herbaceous plants; soil moisture; precipitation; spatiotemporal pattern; Inner Mongolia

\section{Introduction}

Plant phenology (e.g., bud-burst, leaf unfolding, flowering and leaf senescence) is a key indicator of climate dynamics. Changes in phenology influence almost all biophysical and biogeochemical processes on the land surface (Chen et al., 2016; Fu et al., 2018), including water, carbon and nutrient cycles, plant diversity and ecosystem productivity (Miller-Rushing et al., 2010; Richardson et al., 2013; Ding et al., 2015; Liu et al., 2017; Tao

Received: 2019-04-28 Accepted: 2019-09-17

Foundation: National Key R\&D Program of China, No.2018YFA0606102; National Natural Science Foundation of China, No.41771056, No.41901014

Author: Tao Zexing, PhD, specialized in climate change and phenology. E-mail: taozx.12s@igsnrr.ac.cn

*Corresponding author: Dai Junhu, Professor, E-mail: daijh@igsnrr.ac.cn 
et al., 2018). Therefore, it is crucial to simulate plant phenology in the context of climate change.

Phenological modeling is an effective tool for simulating phenological changes in various ecosystems and is also an important component in the terrestrial biosphere model (Jeong and Medvigy, 2014). In recent decades, numerous models have been developed to simulate and predict spring phenology of woody plants in forest ecosystems (Chuine, 2000; Jeong et al., 2013; Yu et al., 2016). In most of these models, temperature is the main factor triggering the onset of spring phenology through chilling and heating processes (Lebourgeois et al., 2010; Ge et al., 2014). However, temperature-based models cannot simulate the spring phenology of herbaceous plants as accurately as that of woody plants (Botta et al., 2000) because the development of herbaceous plants also depends largely on water availability, especially in arid and semi-arid regions (Tao et al., 2017; Whitecross et al., 2017; Ren et al., 2018).

Many studies have demonstrated that precipitation exerts a significant influence on the spring phenology of herbaceous plants, although this impact shows different intensities and directions in different areas (Cleland et al., 2006; Bradley et al., 2011; Fu et al., 2014b). Based on these findings, Chen et al. (2014) developed two modified models considering the impacts of temperature and precipitation for simulating the green-up date of three dominant grass species in Inner Mongolia from 1983 to 2009 and found that the modified models showed higher efficiency than conventional thermal models at about half of the sites (Chen et al., 2014). The effect of precipitation was also integrated into the terrestrial ecosystem process model Biome-BGC, in which the growing season begins when both the accumulated soil temperature and accumulated precipitation exceed specific critical values (White et al., 1997; Fu et al., 2014a). However, additional parameters may not always improve model accuracy (White et al., 1997). Since a considerable part of precipitation can be converted into evaporation and other forms, precipitation cannot directly reflect the available supply of water to vegetation (Yu et al., 2003). Instead, soil moisture, as many studies suggest, may directly control the spring phenology of grassland in middle latitude steppe (Jin et al., 2013; Liu et al., 2013). However, there are very few phenological models taking the effect of soil moisture into account. One model considering the impact of soil moisture performed better than the conventional temperature-based models in simulating the bud-burst date of two dominant grass species in a steppe ecosystem of China (Yuan et al., 2007). Overall, however, it is still difficult to simulate the spring phenology of herbaceous plants precisely. Different herbaceous plants may respond diversely to climatic factors (Munson and Long, 2017), and models developed for one species are not necessarily applicable to others (Chen et al., 2014). Most phenological models for herbaceous plants are calibrated using observation data from limited sites and cannot be used for phenological prediction at a regional scale (Fu and Pan, 2011).

Grassland accounts for about $30 \%$ of the land surface area of Earth. Compared with forest, the primary productivity, species composition and carbon balance of grassland, which are all impacted by phenology, are more sensitive to changes in water conditions (Peters et al., 2010; Booker et al., 2013; Wu and Chen, 2013). Therefore, it is important to develop phenological models of grassland or herbaceous plants by considering the effects of both temperature and moisture. The temperate steppe of Inner Mongolia, typical of grassland ecosystems throughout the world (Li et al., 2016), is an ideal place for investigating how to 
build a model for simulating the spring phenology of herbaceous plants. In this study, we (1) analyzed the correlations between bud-burst dates of four common herbaceous plants and multiple climatic factors (temperature, precipitation and soil moisture); (2) developed spring phenological models considering the effects of multiple climatic factors; and (3) investigated the spatiotemporal pattern of spring phenology over the past 30 years based on bud-burst dates (BBDs) simulated by the optimal models.

\section{Materials and methods}

\subsection{Data sources}

Four common herbaceous plants in the temperate steppe of Inner Mongolia, China, were selected for analysis: Xanthium sibiricum, Plantago asiatica, Iris lactea and Taraxacum mongolicum (Table 1). All species except $X$. sibiricum are perennial plants. Observations of the BBDs from 1981 to 2012 at 20 sites in Inner Mongolia were organized and conducted by the National Meteorological Information Center of China (Table 2). The BBD refers to the date when shoots begin to grow from the ground. The location of the observation sites for each species is shown in Figure 1.

Table 1 Summary of four herbaceous plants investigated in this study

\begin{tabular}{ccccc}
\hline Species number & Scientific name & Life form & Mean BBD (day of the year) & Number of records \\
\hline 1 & Xanthium sibiricum & Annual & 127 & 247 \\
2 & Plantago asiatica & Perennial & 109 & 425 \\
3 & Iris lactea & Perennial & 100 & 421 \\
4 & Taraxacum mongolicum & Perennial & 103 & 512 \\
\hline
\end{tabular}

Table 2 Summary of observation sites in this study

\begin{tabular}{|c|c|c|c|c|c|c|}
\hline Site number & Site name & Long. $\left({ }^{\circ} \mathrm{E}\right)$ & Lat. $\left({ }^{\circ} \mathrm{N}\right)$ & Ele. (m) & Winter $\mathrm{T}\left({ }^{\circ} \mathrm{C}\right)$ & Species \\
\hline 1 & Chifeng & 118.93 & 42.27 & 568.00 & -8.50 & $2,3,4$ \\
\hline 2 & Tongliao & 122.27 & 43.60 & 178.50 & -10.71 & $1,2,4$ \\
\hline 3 & Zhalantun & 122.73 & 48.00 & 306.50 & -15.93 & $1,2,4$ \\
\hline 4 & Xilin Gol & 116.07 & 43.95 & 989.50 & -16.12 & $1,2,3,4$ \\
\hline 5 & Guyang & 110.05 & 41.03 & 1360.40 & -11.08 & $1,2,3,4$ \\
\hline 6 & Urad Qianqi & 108.65 & 40.73 & 1020.40 & -7.68 & $1,2,4$ \\
\hline 7 & Bayannur & 107.4 & 40.77 & 1039.30 & -7.05 & $1,2,3,4$ \\
\hline 8 & Ergun Youqi & 120.18 & 50.25 & 581.40 & -25.34 & $2,3,4$ \\
\hline 9 & Junggar & 111.22 & 39.87 & 1221.40 & -9.99 & $1,2,4$ \\
\hline 10 & Tuquan & 121.55 & 45.40 & 305.30 & -11.29 & $1,2,3,4$ \\
\hline 11 & Hulun Buir & 119.75 & 49.15 & 620.80 & -22.14 & $1,2,3,4$ \\
\hline 12 & Naiman & 120.65 & 42.85 & 362.90 & -9.62 & $1,3,4$ \\
\hline 13 & Xianghuangqi & 113.08 & 42.23 & 1322.10 & -11.99 & $2,3,4$ \\
\hline 14 & Qaharyouyizhongqi & 112.62 & 41.27 & 1747.80 & -13.68 & $2,3,4$ \\
\hline 15 & Wuchuan & 111.45 & 41.10 & 1595.00 & -12.57 & 3,4 \\
\hline 16 & Tumdzuoqi & 111.15 & 40.68 & 1020.30 & -8.24 & $1,2,3,4$ \\
\hline 17 & Taipusi & 115.27 & 41.88 & 1468.90 & -15.16 & $1,2,3,4$ \\
\hline 18 & Bayartuhushuo & 120.03 & 45.07 & 628.30 & -14.86 & $2,3,4$ \\
\hline 19 & Uxinqi & 109.03 & 39.10 & 1312.20 & -7.18 & $1,3,4$ \\
\hline 20 & Jilantai & 105.38 & 39.08 & 1235.00 & -4.25 & $1,3,4$ \\
\hline
\end{tabular}

Note: Long., Lat., Ele. and Winter T indicate longitude, latitude, elevation, and winter (previous December to February) temperature, respectively. Species number: 1. Xanthium sibiricum; 2. Plantago asiatica; 3. Iris lactea; 4. Taraxacum mongolicum. 


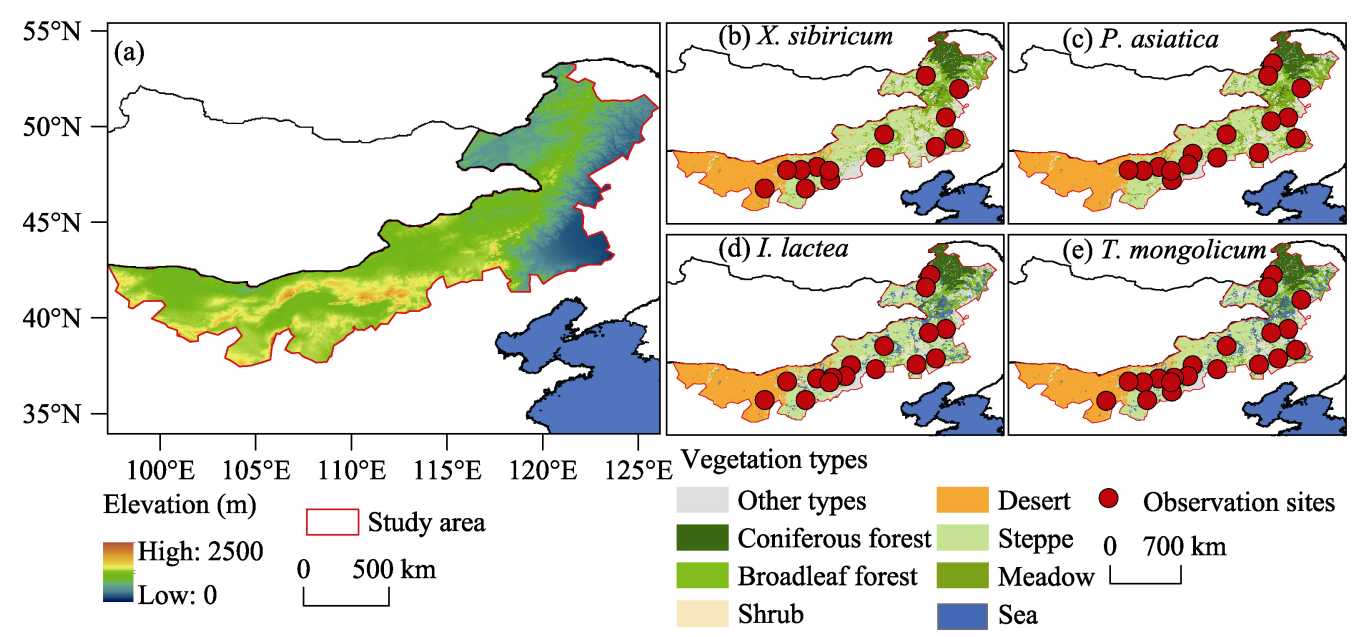

Figure 1 Location and terrain of the Inner Mongolia grassland. Red circles indicate the locations of phenological observation sites for four species.

Meteorological data for near-surface mean temperature and precipitation during 1980-2015 were derived from the China Meteorological Forcing Dataset, with a temporal and spatial resolution of $3 \mathrm{~h}$ and $0.1^{\circ}$, respectively (He and Yang, 2011). Soil moisture data were obtained from the global Essential Climate Variable (ECV) soil moisture dataset (ESA CCI SM v04.2). These consisted of daily soil volumetric water content data from 1978 to 2016 with a spatial resolution of $0.25^{\circ}$. A cubic spline function was used to interpolate missing data in the soil moisture time series. For model calibration, the climate parameters at each site were represented by those in the nearest pixel of gridded climate data.

\subsection{Methods}

\subsubsection{Identifying the influencing factors of spring phenology}

The following four climatic factors we considered, which may have potential impacts on the BBD of herbaceous plants: (1) growing degree days (GDD), calculated as accumulated temperature above $0^{\circ} \mathrm{C}$ from January 1st to the mean BBD (Hänninen, 1990; Cong et al., 2017); (2) chilling days (CD), defined as the number of days below $0^{\circ} \mathrm{C}$ from the previous October 1st to the mean BBD (Cong et al., 2017); (3) accumulated precipitation (AP) from January 1 st to the mean BBD; (4) soil moisture (SM), measured as the mean soil volumetric water content from January 1 st to the mean BBD (Liu et al., 2013).

For each species, all BBD records for each year and site were used to perform partial correlation analysis between BBD and one climatic factor with the influence of the other factors removed. The results showed that the BBD of all species was significantly correlated with GDD and preseason SM (Table 3). For P. asiatica, I. lacteal and T. mongolicum, the correlations between $\mathrm{BBD}$ and $\mathrm{SM}$ were negative, suggesting that greater soil moisture would result in an earlier BBD. Accumulated preseason precipitation affected the BBD of $I$. lactea significantly $(p<0.01)$. However, no species responded to $\mathrm{CD}$ significantly. Therefore, we considered three factors (GDD, AP and SM) in the following phenological models. 
Table 3 Partial correlation coefficients between the bud-burst date and climatic factors for each species

\begin{tabular}{cccccc}
\hline Species number & Species & GDD & CD & AP & SM \\
\hline 1 & X. sibiricum & $-0.16^{*}$ & 0.13 & 0.07 & $0.16^{*}$ \\
2 & P. asiatica & $-0.15^{* *}$ & -0.01 & -0.03 & $-0.16^{* *}$ \\
3 & I. lactea & $-0.13^{*}$ & 0.05 & $-0.12^{*}$ & $-0.14^{*}$ \\
4 & T. mongolicum & $-0.12^{*}$ & 0.03 & -0.01 & $-0.13^{* *}$ \\
\hline
\end{tabular}

GDD: growing degree days; CD: chilling days; AP: accumulated precipitation; SM: soil moisture. ${ }^{* *}: p<0.01,{ }^{*}$ : $p<0.05$

\subsubsection{Model construction}

The spring warming (SW) model and temporal-spatial coupling (TSC) model were first used to simulate the BBD of each species. These two models only considered the effects of GDD.

(1) SW model

The SW model predicts the spring phenophase to occur at day $y$ when the accumulated temperature reaches a threshold $F_{0}$ (Hunter and Lechowicz, 1992). The accumulated temperature is determined by a specific temperature level $T_{b}$ and a predetermined starting date $t_{0}$. The equation can be expressed as:

$$
\sum_{t_{o}}^{y} \max \left(0, x_{t}-T_{b}\right)=F_{0}
$$

where $x_{t}$ is the daily mean temperature at date $t$.

(2) TSC model

The SW model uses a fixed GDD threshold $\left(F_{0}\right)$ among different years and sites. In the TSC model, the GDD threshold becomes a function of winter temperature, because a colder winter may lead to a lower threshold of $F_{w}$ (Ge et al., 2014). The function for $F_{w}$ is:

$$
F_{w}=a+b \times e^{\frac{T_{w i n}}{f}}
$$

where $a, b$ and $f$ are parameters. $T_{\text {win }}$ is the mean December-February temperature for each year at each site.

(3) Models considering the effects of precipitation and soil moisture

Subsequently, the effects of water, expressed as precipitation or soil moisture, were added into the SW and TSC models. The modified models were established according to different hypotheses.

Hypothesis 1: the mean preseason soil moisture or precipitation is assumed to influence the threshold of accumulated temperature. The effect can be depicted by either of the following two equations:

$$
\begin{gathered}
F_{S M 1}=F_{0}+n_{1} \times \overline{S M} \\
F_{P R E 1}=F_{0}+n_{1} \times \overline{P R E}
\end{gathered}
$$

where $\overline{S M}$ and $\overline{P R E}$ are the mean soil moisture and mean precipitation from $t_{0}$ to the mean phenophase, respectively. $n_{1}$ is a parameter. $F_{S M 1}$ and $F_{P R E 1}$ are the new thresholds of GDD.

Hypothesis 2: soil moisture or precipitation influence the daily growth of herbaceous 
plants from $t_{0}$ to $y$ through an additional effect with temperature, which can be described as:

$$
\begin{gathered}
F_{S M 2}=\sum_{t_{0}}^{y}\left(\max \left(0, x_{t}-T_{b}\right)+k_{1} \times S M_{t}\right) \\
F_{P R E 2}=\sum_{t_{0}}^{y}\left(\max \left(0, x_{t}-T_{b}\right)+k_{1} \times P R E_{t}\right)
\end{gathered}
$$

where $x_{t}, S M_{t}$ and $P R E_{t}$ are the mean temperature, soil moisture and precipitation at date $t$, respectively. $k_{1}$ is a species-specific parameter. $F_{S M 2}$ and $F_{P R E 2}$ are the new thresholds of GDD.

Hypothesis 3: soil moisture or precipitation can adjust the daily accumulation of temperature through a multiplicative effect with the following equation:

$$
\begin{gathered}
F_{S M 3}=\sum_{t_{0}}^{y}\left(\max \left(0, x_{t}-T_{b}\right) \times\left(1+k_{2} \times S M_{t}\right)\right) \\
F_{P R E 3}=\sum_{t_{0}}^{y}\left(\max \left(0, x_{t}-T_{b}\right) \times\left(1+k_{2} \times P R E_{t}\right)\right)
\end{gathered}
$$

where $k_{2}$ is a species-specific parameter. $F_{S M 3}$ and $F_{P R E 3}$ are the new thresholds of GDD.

In total, 14 models were constructed including two thermal models, six temperature-SM

\begin{tabular}{|c|c|c|c|c|}
\hline Number & Model & Influencing factors & Equations & Parameters \\
\hline 1 & SW & Temperature & (1) & $t_{0}, T_{b}, F_{0}$ \\
\hline 2 & $\mathrm{TSC}$ & Temperature & $(1),(2)$ & $t_{0}, T_{b}, a, b, f$ \\
\hline 3 & $\mathrm{SW}-\mathrm{H}_{1}$ & Temperature, soil moisture & $(1),(3)$ & $t_{0}, T_{b}, F_{S M 1}, n_{1}$ \\
\hline 4 & TSC-H & Temperature, soil moisture & $(1),(2),(3)$ & $t_{0}, T_{b}, a, b, f, n_{1}$ \\
\hline 5 & $\mathrm{SW}-\mathrm{H}_{2}$ & Temperature, soil moisture & $(1),(5)$ & $t_{0}, T_{b}, F_{S M 2}, k_{1}$ \\
\hline 6 & TSC- $\mathrm{H}_{2}$ & Temperature, soil moisture & $(1),(2),(5)$ & $t_{0}, T_{b}, a, b, f, k_{1}$ \\
\hline 7 & $\mathrm{SW}-\mathrm{H}_{3}$ & Temperature, soil moisture & $(1),(7)$ & $t_{0}, T_{b}, F_{S M 3}, k_{2}$ \\
\hline 8 & $\mathrm{TSC}-\mathrm{H}_{3}$ & Temperature, soil moisture & $(1),(2),(7)$ & $t_{0}, T_{b}, a, b, f, k_{2}$ \\
\hline 9 & $\mathrm{SW}-\mathrm{P}_{1}$ & Temperature, precipitation & $(1),(4)$ & $t_{0}, T_{b}, F_{P R E 1}, n_{1}$ \\
\hline 10 & TSC-P 1 & Temperature, precipitation & $(1),(2),(4)$ & $t_{0}, T_{b}, a, b, f, n_{1}$ \\
\hline 11 & $\mathrm{SW}-\mathrm{P}_{2}$ & Temperature, precipitation & $(1),(6)$ & $t_{0}, T_{b}, F_{P R E 2}, k_{1}$ \\
\hline 12 & TSC-P 2 & Temperature, precipitation & $(1),(2),(6)$ & $t_{0}, T_{b}, a, b, f, k_{1}$ \\
\hline 13 & $\mathrm{SW}-\mathrm{P}_{3}$ & Temperature, precipitation & $(1),(8)$ & $t_{0}, T_{b}, F_{P R E 3}, k_{2}$ \\
\hline 14 & TSC-P 3 & Temperature, precipitation & $(1),(2),(8)$ & $t_{0}, T_{b}, a, b, f, k_{2}$ \\
\hline
\end{tabular}
(soil temperature) models and six temperature-precipitation models for simulating the BBD of the four species (Table 4).

Table 4 Spring phenological models constructed in this study

\subsubsection{Model calibration and validation}

The BBD records from all sites and years were used to fit and validate each type of model. By using the observation data from odd years, the parameter values of the models were determined by minimizing the sum of squared errors through a simulated annealing algorithm 
(Chuine et al., 1998). The observation data in even years were used for cross-validation. The coefficient of determination $\left(R^{2}\right)$, root mean square error (RMSE, Eq. 9) and Akaike information criterion ( $A I C$, Eq. 10) were used to compare the performance of the 14 models. For each species, the model with the largest $R^{2}$ and the smallest $R M S E$ and $A I C$ in cross-validation was determined to be the optimal model.

$$
\begin{gathered}
R M S E=\sqrt{\frac{\sum_{i=1}^{n}\left(o b s_{i}-p r e_{i}\right)^{2}}{n}} \\
A I C=n \times \ln \left(\frac{\sum_{i=1}^{n}\left(o b s_{i}-p r e_{i}\right)^{2}}{n}\right)+2 \times(k+1)
\end{gathered}
$$

where $o b s_{i}$ and pre $_{i}$ represent the observed and simulated BBD for the $i$-th record, respectively. $n$ is the number of records. $k$ is the number of model parameters.

\subsubsection{Spatial patterns of BBD variability}

The optimal model was applied with gridded climate data to simulate the year-by-year BBD of each species across Inner Mongolia during 1980-2015. All the phenological observation sites were distributed in the central part of Inner Mongolia where the vegetation was dominated by steppe and meadow. Therefore, the BBD of the four species in steppe and meadow regions was simulated. The $\mathrm{BBD}$ trend in each pixel was analyzed using a linear regression method. Spatiotemporal patterns of changes in the BBD of the four herbaceous plants were analyzed using Matlab R2017a. Figures were drawn using Arcgis 10.2 and OriginPro 2016.

\section{Results}

\subsection{Validation of phenological models}

After fitting models for each species, the parameters (provided in Table 5) and validity results (provided in Table 6) of each model were defined. During internal validation, the $\mathrm{SW}-\mathrm{H}_{3}$ model exhibited better accuracy than the other models in modeling the BBD of $X$. sibiricum. For the other three species, the $\mathrm{TSC}-\mathrm{H}_{2}$ model outperformed the other models, reducing the RMSE and AIC by $4.97 \%-29.82 \%$ (mean: $18.34 \%$ ) and $1.71 \%-13.26 \%$ (mean: $8.16 \%$ ) compared with other models, respectively.

The optimal phenological models obtained for each species in cross-validation are shown in Table 5. Comparisons between the observed BBD and the BBD simulated by the optimal model are shown in Figure 2. The $\mathrm{SW}-\mathrm{H}_{3}$ model exhibited the best predictive power for $X$. sibiricum with an $R^{2}$ of 0.41, RMSE of 11.97 days and AIC of 397.19. For P. asiatica and T. mongolicum, the TSC- $\mathrm{H}_{2}$ model showed the highest simulation efficiency with the smallest $R M S E$ and $A I C$ among all 14 models. It could explain $23 \%(p<0.01)$ and $19 \%(p<0.01)$ of the observed BBD for $P$. asiatica and T. mongolicum, respectively. The BBD of I. lactea could be better fitted using the TSC- $\mathrm{P}_{3}$ model, which exhibited a larger goodness of fit $\left(R^{2}=0.17, p<0.01\right)$ than the other models (Table 6). 
Table 5 Results of parameter fitting of the optimal spring phenological model for each species

\begin{tabular}{|c|c|c|c|c|c|c|c|}
\hline Species & Optimal model & & & Paran & values & & \\
\hline \multirow{2}{*}{ X. sibiricum } & \multirow{2}{*}{$\mathrm{SW}-\mathrm{H}_{3}$} & $t_{0}$ & $T_{b}$ & & $F$ & & $k_{2}$ \\
\hline & & 18 & 0.66 & & 202.91 & & -2.7 \\
\hline \multirow{2}{*}{ P. asiatica } & \multirow{2}{*}{ TSC- $\mathrm{H}_{2}$} & $t_{0}$ & $T_{b}$ & $a$ & $b$ & $f$ & $k_{1}$ \\
\hline & & 29 & 9.46 & 58.54 & 112 & 2.43 & 4.6 \\
\hline \multirow{2}{*}{ I. lactea } & \multirow{2}{*}{ TSC-P } & $t_{0}$ & $T_{b}$ & $a$ & $b$ & $f$ & $n_{1}$ \\
\hline & & 27 & 2.3 & 50.67 & 188.27 & 4.78 & 1.94 \\
\hline \multirow{2}{*}{ T. mongolicum } & \multirow{2}{*}{ TSC- $\mathrm{H}_{2}$} & $t_{0}$ & $T_{b}$ & $a$ & $b$ & $f$ & $k_{1}$ \\
\hline & & 22 & 8.29 & 69.16 & 154.92 & 2.26 & 4.85 \\
\hline
\end{tabular}

$* *: p<0.01, *: p<0.05$

Table 6 Validation of the 14 phenological models for simulating the bud-burst dates of four species in Inner Mongolia

\begin{tabular}{|c|c|c|c|c|c|c|c|c|c|}
\hline \multirow[b]{2}{*}{ Species } & \multirow[b]{2}{*}{ Model } & \multicolumn{4}{|c|}{ Internal validation } & \multicolumn{4}{|c|}{ Cross-validation } \\
\hline & & $\begin{array}{l}\text { Record } \\
\text { number }\end{array}$ & $R M S E$ & $R^{2}$ & $A I C$ & $\begin{array}{l}\text { Record } \\
\text { number }\end{array}$ & $R M S E$ & $R^{2}$ & $A I C$ \\
\hline \multirow{14}{*}{ X. sibiricum } & SW & 86 & 11.90 & $0.36 * *$ & 433.98 & 78 & 12.82 & $0.33 * *$ & 406.01 \\
\hline & TSC & 86 & 11.82 & $0.34 * *$ & 436.85 & 78 & 12.65 & $0.33 * *$ & 407.86 \\
\hline & SW-H & 86 & 11.91 & $0.35 * *$ & 436.07 & 78 & 12.69 & $0.35 * *$ & 406.32 \\
\hline & TSC- $\mathrm{H}_{1}$ & 86 & 11.81 & $0.34 * *$ & 440.65 & 78 & 12.64 & $0.33 * *$ & 411.73 \\
\hline & SW-H ${ }_{2}$ & 86 & 11.87 & $0.36^{* *}$ & 435.55 & 78 & 12.74 & $0.35 * *$ & 406.96 \\
\hline & TSC- $\mathrm{H}_{2}$ & 86 & 11.73 & $0.35 * *$ & 437.49 & 78 & 12.59 & $0.34 * *$ & 409.07 \\
\hline & $\mathrm{SW}-\mathrm{H}_{3}$ & 86 & 11.63 & $0.39 * *$ & 432.07 & 78 & 11.97 & $0.41 * *$ & 397.19 \\
\hline & $\mathrm{TSC}-\mathrm{H}_{3}$ & 86 & 11.41 & $0.39 * *$ & 432.67 & 78 & 12.02 & $0.41 * *$ & 401.92 \\
\hline & SW-P ${ }_{1}$ & 86 & 13.19 & $0.35 * *$ & 453.73 & 78 & 14.97 & $0.23 * *$ & 432.18 \\
\hline & TSC-P $_{1}$ & 86 & 11.78 & $0.35 * *$ & 438.11 & 78 & 12.67 & $0.33 * *$ & 410.11 \\
\hline & $\mathrm{SW}-\mathrm{P}_{2}$ & 86 & 11.91 & $0.36^{* *}$ & 436.13 & 78 & 12.68 & $0.35 * *$ & 406.29 \\
\hline & TSC-P ${ }_{2}$ & 86 & 11.84 & $0.33 * *$ & 439.05 & 78 & 12.88 & $0.31 * *$ & 412.66 \\
\hline & $\mathrm{SW}-\mathrm{P}_{3}$ & 86 & 11.90 & $0.36 * *$ & 435.94 & 78 & 12.72 & $0.34 * *$ & 406.69 \\
\hline & $\mathrm{TSC}^{\mathrm{P}} \mathrm{P}_{3}$ & 86 & 11.82 & $0.34 * *$ & 438.77 & 78 & 12.55 & $0.34 * *$ & 408.65 \\
\hline \multirow{12}{*}{ P. asiatica } & SW & 128 & 10.21 & $0.16 * *$ & 602.74 & 122 & 10.68 & $0.22 * *$ & 585.91 \\
\hline & $\mathrm{TSC}$ & 128 & 8.90 & $0.12 * *$ & 571.74 & 122 & 9.30 & $0.26^{* *}$ & 556.20 \\
\hline & SW-H & 128 & 10.22 & $0.16^{* *}$ & 605.15 & 122 & 10.68 & $0.22 * *$ & 587.91 \\
\hline & TSC- $\mathrm{H}_{1}$ & 128 & 8.89 & $0.12 * *$ & 575.31 & 122 & 9.29 & $0.26 * *$ & 559.88 \\
\hline & SW- $\mathrm{H}_{2}$ & 128 & 8.26 & $0.14 * *$ & 550.67 & 122 & 9.24 & $0.22 * *$ & 552.43 \\
\hline & TSC- $\mathrm{H}_{2}$ & 128 & 7.81 & $0.16^{* *}$ & 540.09 & 122 & 9.03 & $0.23 * *$ & 550.91 \\
\hline & SW-H 3 & 128 & 10.32 & $0.16^{* *}$ & 607.48 & 122 & 10.53 & $0.22 * *$ & 584.46 \\
\hline & $\mathrm{TSC} \mathrm{H}_{3}$ & 128 & 8.91 & $0.13 * *$ & 573.86 & 122 & 9.44 & $0.25 * *$ & 561.67 \\
\hline & SW-P ${ }_{1}$ & 128 & 11.59 & $0.12 * *$ & 637.18 & 122 & 11.17 & $0.20 * *$ & 598.93 \\
\hline & TSC-P ${ }_{1}$ & 128 & 8.89 & $0.11 * *$ & 573.24 & 122 & 9.27 & $0.26^{* *}$ & 557.40 \\
\hline & SW-P ${ }_{2}$ & 128 & 9.98 & $0.16^{* *}$ & 598.93 & 122 & 10.34 & $0.22 * *$ & 579.89 \\
\hline & TSC-P ${ }_{2}$ & 128 & 8.84 & $0.12 * *$ & 571.94 & 122 & 9.26 & $0.26^{* *}$ & 557.12 \\
\hline
\end{tabular}


(Continued)

\begin{tabular}{|c|c|c|c|c|c|c|c|c|c|}
\hline \multirow[b]{2}{*}{ Species } & \multirow[b]{2}{*}{ Model } & \multicolumn{4}{|c|}{ Internal validation } & \multicolumn{4}{|c|}{ Cross-validation } \\
\hline & & $\begin{array}{l}\text { Record } \\
\text { number }\end{array}$ & $R M S E$ & $R^{2}$ & $A I C$ & $\begin{array}{l}\text { Record } \\
\text { number }\end{array}$ & $R M S E$ & $R^{2}$ & $A I C$ \\
\hline & SW-P 3 & 128 & 9.81 & $0.15 * *$ & 594.65 & 122 & 10.14 & $0.23 * *$ & 575.27 \\
\hline & TSC-P $_{3}$ & 128 & 8.54 & $0.13^{* *}$ & 562.96 & 122 & 9.06 & $0.25 * *$ & 551.79 \\
\hline \multirow{14}{*}{ I. lactea } & SW & 134 & 12.68 & 0.02 & 688.75 & 129 & 13.28 & $0.08 * *$ & 675.20 \\
\hline & TSC & 134 & 10.59 & 0.03 & 644.39 & 129 & 11.30 & $0.11 * *$ & 637.58 \\
\hline & SW-H & 134 & 12.68 & 0.02 & 690.75 & 129 & 15.85 & $0.05^{*}$ & 722.86 \\
\hline & TSC- $\mathrm{H}_{1}$ & 134 & 10.58 & $0.03 *$ & 648.20 & 129 & 13.11 & $0.06^{*}$ & 679.86 \\
\hline & SW- $\mathrm{H}_{2}$ & 134 & 9.48 & $0.04 *$ & 612.66 & 129 & 9.99 & $0.12 * *$ & 603.71 \\
\hline & TSC- $\mathrm{H}_{2}$ & 134 & 8.92 & $0.05^{* *}$ & 600.54 & 129 & 9.87 & $0.11 * *$ & 604.59 \\
\hline & SW- $\mathrm{H}_{3}$ & 134 & 12.31 & 0.03 & 682.74 & 129 & 13.15 & $0.09 * *$ & 674.66 \\
\hline & $\mathrm{TSC}-\mathrm{H}_{3}$ & 134 & 10.53 & $0.03 *$ & 644.89 & 129 & 11.25 & $0.11 * *$ & 638.47 \\
\hline & SW-P ${ }_{1}$ & 134 & 10.52 & 0.03 & 644.66 & 129 & 11.23 & $0.11 * *$ & 637.90 \\
\hline & TSC-P 1 & 134 & 14.11 & 0.01 & 719.39 & 129 & 14.63 & 0.02 & 702.25 \\
\hline & SW-P 2 & 134 & 12.39 & $0.05^{*}$ & 684.60 & 129 & 12.63 & $0.10 * *$ & 664.24 \\
\hline & TSC-P ${ }_{2}$ & 134 & 10.22 & $0.05^{* *}$ & 636.80 & 129 & 11.14 & $0.14 * *$ & 635.91 \\
\hline & $\mathrm{SW}-\mathrm{P}_{3}$ & 134 & 11.67 & $0.06^{* *}$ & 668.59 & 129 & 12.32 & $0.12 * *$ & 657.80 \\
\hline & TSC-P $_{3}$ & 134 & 9.48 & $0.09 * *$ & 616.73 & 129 & 10.00 & $0.17 * *$ & 608.14 \\
\hline \multirow{14}{*}{ T. mongolicum } & SW & 167 & 12.81 & $0.03 *$ & 859.71 & 161 & 12.78 & $0.12 * *$ & 828.36 \\
\hline & $\mathrm{TSC}$ & 167 & 10.40 & $0.03 *$ & 794.03 & 161 & 11.46 & $0.12 * *$ & 797.21 \\
\hline & $\mathrm{SW}-\mathrm{H}_{1}$ & 167 & 12.81 & $0.03^{*}$ & 861.71 & 161 & 16.50 & $0.06 * *$ & 912.61 \\
\hline & TSC- $\mathrm{H}_{1}$ & 167 & 10.40 & $0.03^{*}$ & 798.03 & 161 & 15.58 & $0.05^{*}$ & 900.16 \\
\hline & SW- $\mathrm{H}_{2}$ & 167 & 9.46 & $0.05^{* *}$ & 760.50 & 161 & 11.72 & $0.16^{* *}$ & 802.66 \\
\hline & TSC- $\mathrm{H}_{2}$ & 167 & 8.99 & $0.05 * *$ & 747.47 & 161 & 10.56 & $0.19 * *$ & 772.95 \\
\hline & $\mathrm{SW}-\mathrm{H}_{3}$ & 167 & 12.78 & $0.04^{*}$ & 860.87 & 161 & 12.75 & $0.12 * *$ & 829.70 \\
\hline & $\mathrm{TSC} \mathrm{H}_{3}$ & 167 & 10.71 & $0.03 *$ & 805.88 & 161 & 11.33 & $0.14 * *$ & 795.62 \\
\hline & SW-P ${ }_{1}$ & 167 & 10.68 & 0.03 & 805.12 & 161 & 11.35 & $0.14 * *$ & 796.13 \\
\hline & TSC-P 1 & 167 & 13.88 & 0.02 & 888.48 & 161 & 13.81 & $0.08 * *$ & 855.33 \\
\hline & SW-P 2 & 167 & 12.57 & $0.03^{*}$ & 855.44 & 161 & 12.92 & $0.11 * *$ & 833.91 \\
\hline & TSC-P ${ }_{2}$ & 167 & 10.73 & $0.03 *$ & 806.63 & 161 & 11.09 & $0.16^{* *}$ & 788.73 \\
\hline & SW-P 3 & 167 & 12.13 & $0.04^{*}$ & 843.63 & 161 & 12.55 & $0.13 * *$ & 824.70 \\
\hline & TSC-P $_{3}$ & 167 & 10.15 & $0.03 *$ & 788.16 & 161 & 10.86 & $0.15^{* *}$ & 782.05 \\
\hline
\end{tabular}

**: $p<0.01, *: p<0.05$

\subsection{Spatiotemporal pattern of changes in BBD}

The mean BBD (1980-2015) simulated by the optimal models for the four species exhibited a consistent pattern in Inner Mongolia steppe and meadow regions (Figure 3). For all species, the earliest BBD occurred in the southwest, while the latest BBD occurred in the northeast of Inner Mongolia. In addition, the species with the latest BBD, i.e., X. sibiricum (mean: day of year 135.30), showed a larger spatial difference in BBD (standard deviation: 13.88 days) than the other species. The species that sprouted earliest, i.e., I. lacteal (mean: day of year 103.10), showed relatively small variation across space (standard deviation: 5.37 days). 


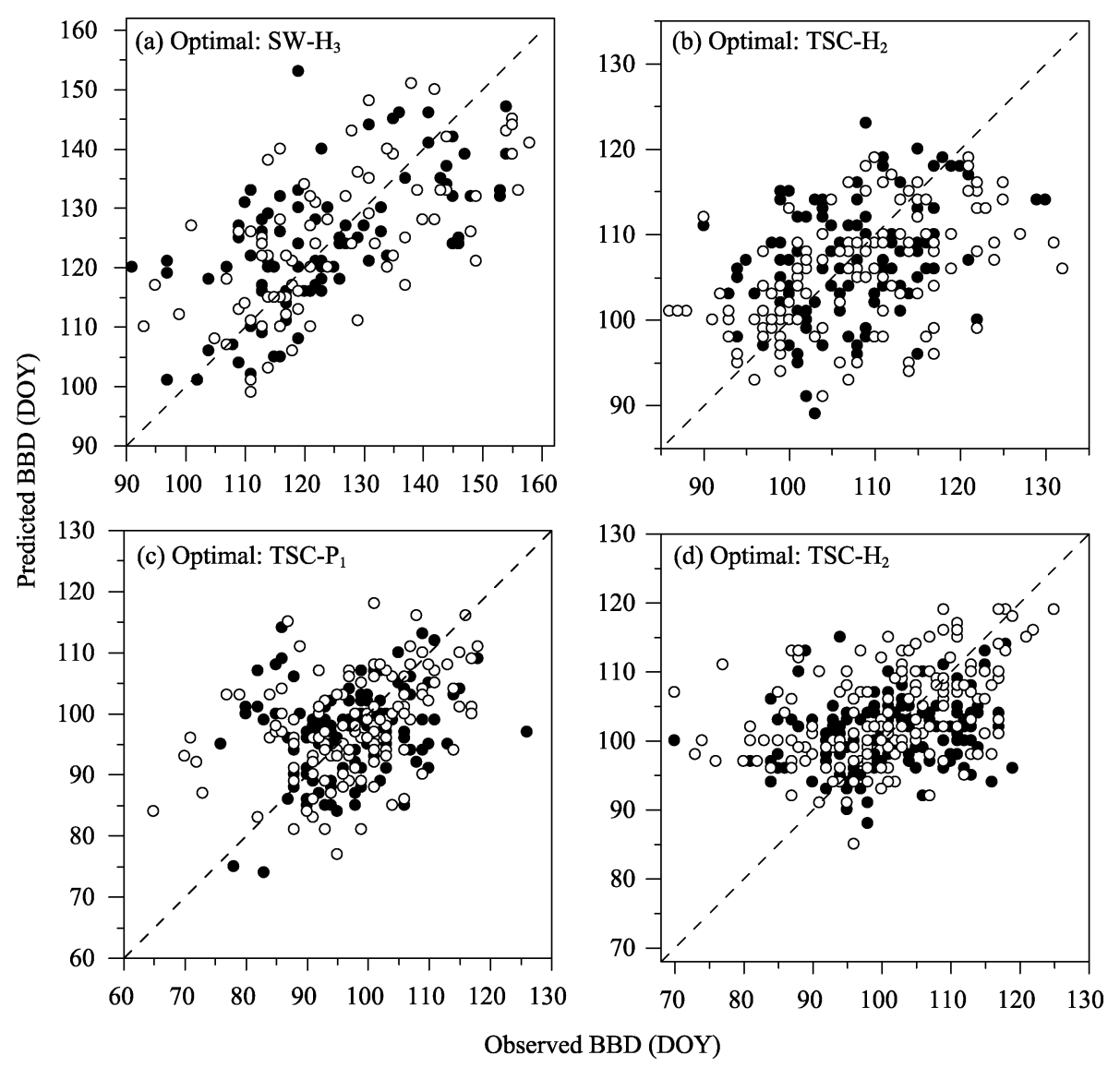

Figure 2 Comparison of observed and simulated bud-burst date (BBD) using the optimal phenological model for (a) Xanthium sibiricum, (b) Plantago asiatica, (c) Iris lactea and (d) Taraxacum mongolicum. Dots and circles represent data in internal validation and cross-validation, respectively. Dashed line is 1:1. DOY: day of the year.

The variation of annual mean BBD was almost synchronous for the four species during the period of 1980-2015 (Figure 4). For X. sibiricum, the BBD was latest in 1980 and earliest in 1998. The latest BBD for all other species occurred in 1995, and the earliest BBD was around 2014. A significant advancing trend was found for each of the species, ranging from -0.23 days/a for $X$. sibiricum $(p<0.01)$ to -0.37 days/a for $P$. asiatica $(p<0.01)$.

An advancing trend (negative value) in the BBD for the four species was found across the majority of Inner Mongolia grassland (Figures 5 and 6). In total, $46.72 \%$ of the pixels showed a significant advancing trend for BBD of $X$. sibiricum $(p<0.01)$, and this trend was most obvious in the southwest. The pixels with delayed BBD for $X$. sibiricum only accounted for $8.50 \%$ of the total area, which mainly occurred in parts of the southeastern region (Figure 6). Regarding $P$. asiatica and T. mongolicum, the trend for BBD was significant $(p<0.05)$ in $66.94 \%$ and $67.81 \%$ of the total area, respectively (Figure 5). An advancing trend larger than 0.5 days/a was found in central region for both species. For I. lacteal, pixels that displayed advancing BBD accounted for more than $99.96 \%$ of the total area $(73.21 \%$ significantly, $p<0.05)$. The advancing trend was more evident in the northeast than in other areas. 

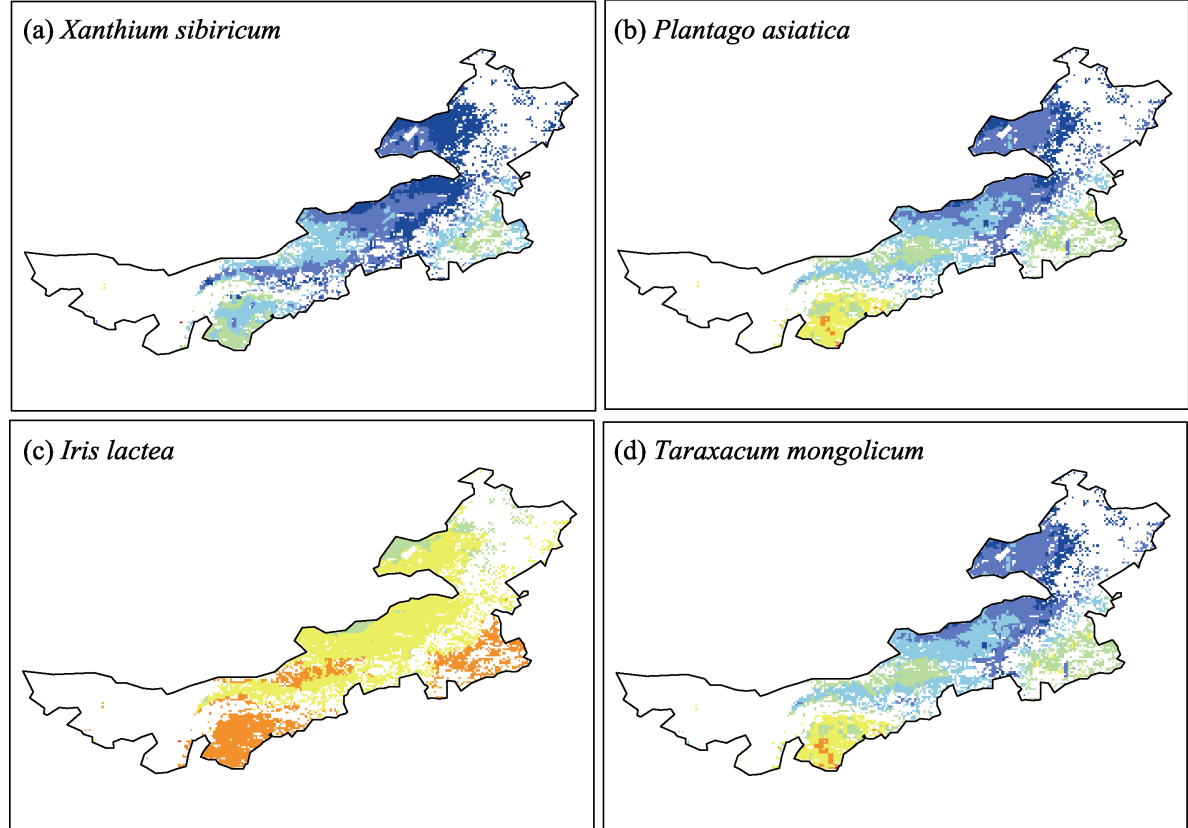

(d) Taraxacum mongolicum

Bud-burst Date (DOY)

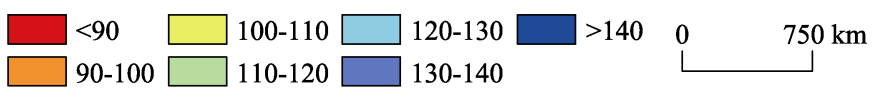

Figure 3 Spatial pattern of the mean bud-burst date for four species in the Inner Mongolia grassland during 1980-2015. DOY: day of the year
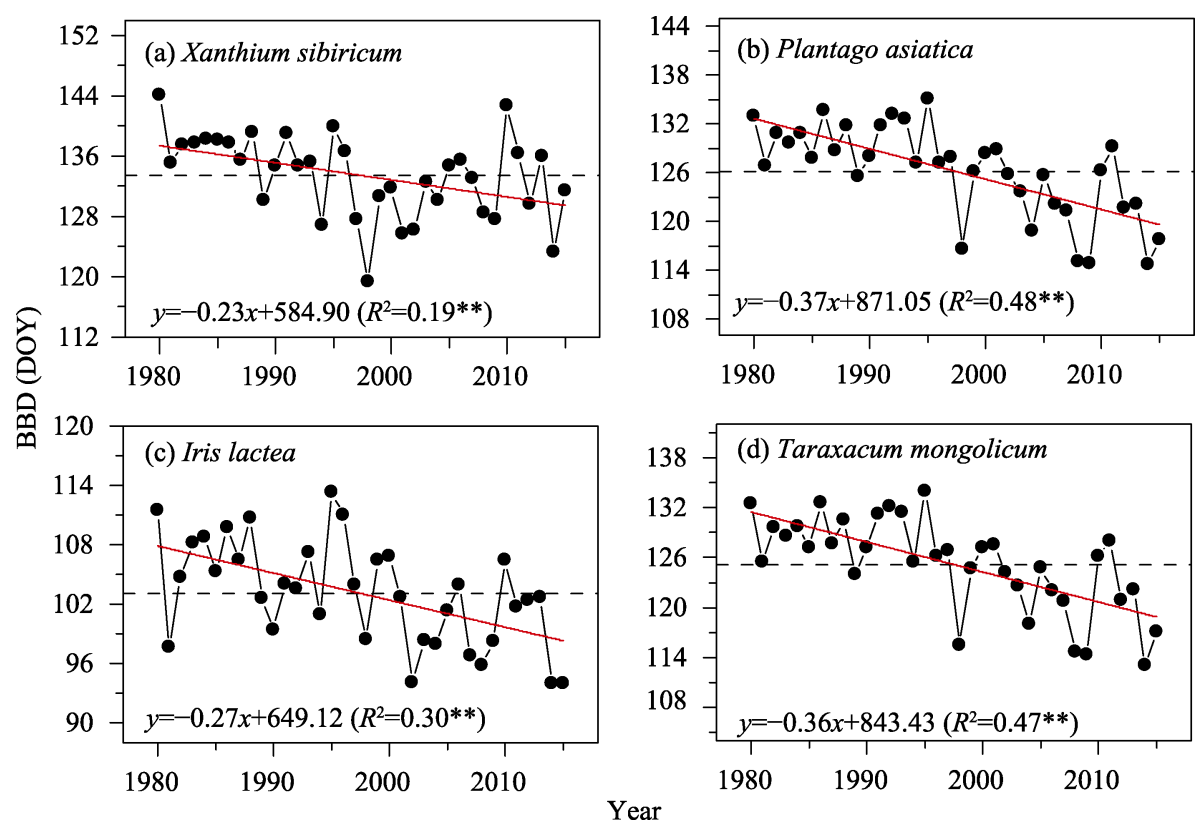

Figure 4 Interannual variation of bud-burst date (BBD) for the four species in the Inner Mongolia grassland during 1980-2015. Red line refers to linear regression and dashed line to the multi-year mean BBD. ${ }^{* *}: p<0.01$ 


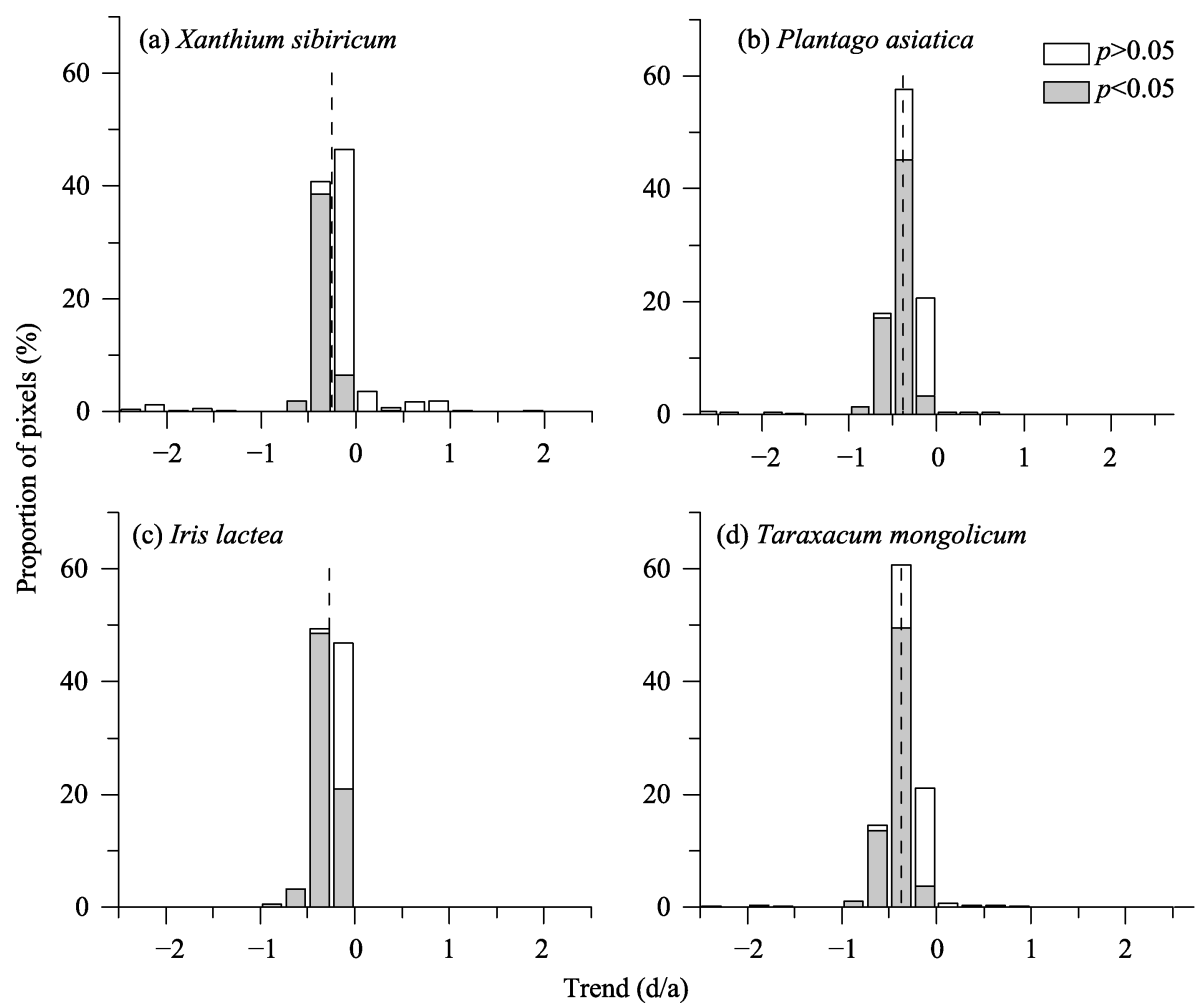

Figure 5 Frequency distribution of the trend in the bud-burst date for four species in the Inner Mongolia grassland during 1980-2015. Dashed line shows the mean linear trend for each species.

\section{Discussion}

\subsection{Factors influencing spring phenology of herbaceous plants}

Through partial correlation analysis, we found a negative correlation between the BBD of all herbaceous plants and preseason temperature, which was in accordance with the results of previous studies (Yuan et al., 2007; Zhu et al., 2018). Therefore, higher spring temperature leads to an earlier green-up date of herbaceous plants.

Besides temperature, water availability is critical for the green-up of herbaceous plants (Cao et al., 2018). However, the mechanisms triggering BBD might differ among species, because precipitation and soil moisture showed divergent correlations with BBD in different species (Table 2). Several studies have identified the influence of precipitation on spring phenology of vegetation (Tao et al., 2017; Whitecross et al., 2017). For example, Fu et al. (2014) reported that the heat requirement for green-up onset was positively correlated with previous winter precipitation at northern middle and high latitudes. Furthermore, soil moisture is thought to be a more straightforward index than precipitation in triggering the green-up onset date of steppe (Li et al., 2016; Wang et al., 2017; White et al., 1997). In this study, we found that the BBD of $P$. asiatica and T. mongolicum was significantly influenced by preseason soil moisture but had a weak correlation with precipitation. 

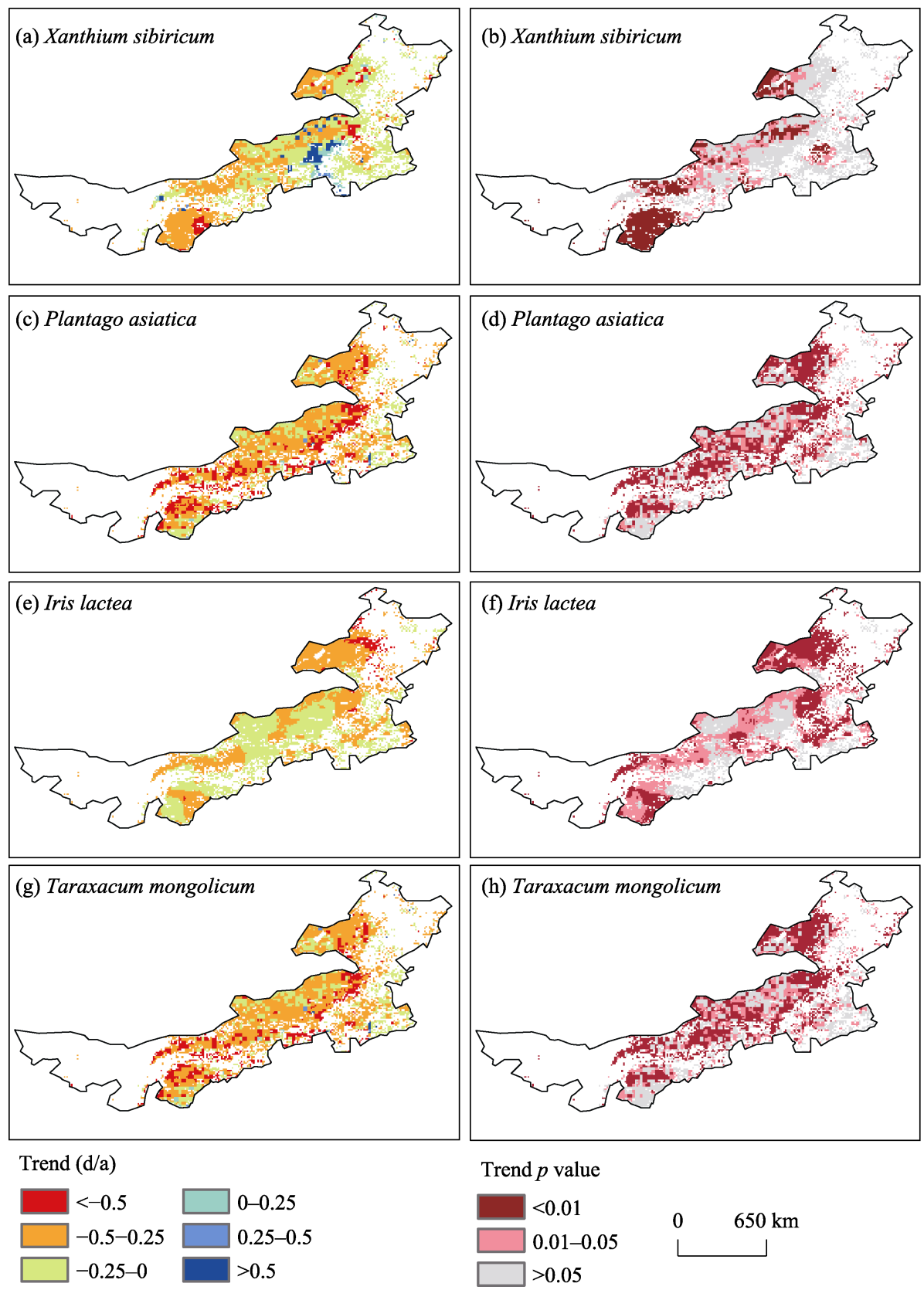

Trend $p$ value

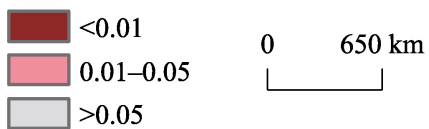

Figure 6 Spatial pattern of the trend in bud-burst date for four species in the Inner Mongolia grassland during 1980-2015. Images on the right represent significance level.

Winter temperature, expressed as chilling days, is considered to have a potential impact on the BBD of herbaceous plants (Cong et al., 2017), but we found no significant correlation between BBD and chilling days in this study. However, our modified models based on the TSC model simulated the BBD of P. asiatica, I. lactea and T. mongolicum better than the corresponding SW-based models, suggesting that changes in winter temperature would alter the heat requirements for the green-up of these species. This was consistent with results 
from several temperate tree species in the Northern Hemisphere (Vihera-Aarnio et al., 2014; Chuine et al., 2016; Chen et al., 2017). However, winter temperature seemed to exert little influence on spring phenology of $X$. sibiricum, probably because the chilling requirement of this species was always fulfilled, even with winter temperatures becoming higher over the past 30 years.

\subsection{Improvement of the spring phenological model for herbaceous plants}

The phenological model of herbaceous plants has been studied less than that of woody plants because the mechanism triggering phenology of herbaceous plants is more complex and inconsistent (Li et al., 2016). To date, most existing models were developed according to the classical thermal models of woody plants (Fu et al., 2014a), or based on the statistical relationship between phenophases and climatic factors (Sun et al., 2018). Only a few studies integrated the effect of temperature and moisture in phenological models of herbaceous plants (Yuan et al., 2007; Chen et al., 2014). In this study, we developed 12 modified models based on different hypotheses to simulate the BBD of four common herbaceous plants in Inner Mongolia. In general, the modified models fit the observed BBD data better with smaller RMSE, smaller $A I C$ and larger $R^{2}$ values compared with the classical models. The $R M S E$ of the optimal model for the four herbaceous plants ranged from 9.03 to 11.97 days, which was slightly larger than the RMSE (7-9 days) when simulating the leaf unfolding dates of six temperate tree species across central Europe (Linkosalo et al., 2006; Basler, 2016). Interestingly, when using the $\mathrm{SW}-\mathrm{H}_{3}$ model to simulate the BBD of $X$. sibiricum at different sites, we found that the RMSE was positively correlated with the site mean annual precipitation during the study period (Pearson's $r=0.59, p<0.01$ ). Thus, the modified model could simulate the spring phenology of $X$. sibiricum better in more arid areas, which supported the conclusion that water was more important to the spring phenology of steppe in arid areas than that in humid areas (Cong et al., 2013; Tao et al., 2017).

\subsection{Changes in spring phenology of herbaceous plants}

Using the optimal models, we simulated the BBD of four herbaceous plants in Inner Mongolia during 1980-2015. The results showed that the BBD of all species advanced significantly in most areas. The overall trend ranged from -0.23 days/a to -0.36 days/a, which was comparable to the trend in green-up date of Stipa baicalensis ( -0.27 days/a) in Ergun city (located in northeastern Inner Mongolia) during 1983-2009 (Li and Han, 2013). In addition, the phenological trend in this study was slightly larger than the mean trend of green-up date of Leymus chinensis (-0.15 days/a) at seven sites in Inner Mongolia during 1983-2002 (Chen and Li, 2009), suggesting that the spring phenology of herbaceous plants was earlier in the most recent decade compared to previous decades (as shown in Figure 4).

\subsection{Implications}

This study confirmed that soil moisture, besides temperature and precipitation, exerted significant influence on the BBD of herbaceous plants. In addition, non-climate factors, such as metal content of soil and human activities, are known to affect spring phenology of herbaceous plants to a certain degree (Ryser and Sauder, 2006; Liu et al., 2018). All these effects 
need to be considered in future phenological models. Furthermore, in order to enhance the reliability of the process-based model, the model still requires validation by physiological experiments (Chew et al., 2012; Xin, 2016; Hänninen et al., 2018).

\section{Conclusions}

In this study, we analyzed the relationship between the BBD of four herbaceous plants and multiple climatic factors in Inner Mongolia. By adding the factors that were significantly correlated with BBD into two thermal models, we established 12 modified models considering the effect of both heat and water. The optimal model with the largest $R^{2}$ and smallest $A I C$ and RMSE in cross-validation was used to simulate the spatiotemporal pattern of BBD for each species from 1980 to 2015. For all species, an increase in temperature led to an advance in the BBD. However, the influence of precipitation and soil moisture was species-specific. For most species, increases in precipitation and soil moisture also promoted the BBD. By considering the effect of soil moisture (three species) or the effect of precipitation (one species), the optimal models simulated the BBD with lower RMSE, smaller AIC and larger $R^{2}$ than classical thermal models. The $R^{2}$ of the optimal models ranged from 0.17 to 0.41 , and the RMSE ranged from 9.03 to 11.97 days. Simulation results of the optimal models revealed an advancing trend in the BBD of the four species in most parts of Inner Mongolia grassland over the past 35 years, and this advancing trend was significant in $46.72 \%-73.21 \%$ of areas. In addition, we noticed that the species with the latest BBD, e.g. $X$. sibiricum (mean: day of year 135.30) showed a larger spatial difference in BBD (standard deviation: 13.88 days) than species with earlier BBD.

\section{References}

Basler D, 2016. Evaluating phenological models for the prediction of leaf-out dates in six temperate tree species across central Europe. Agricultural and Forest Meteorology, 217: 10-21.

Booker K, Huntsinger L, Bartolome J W et al., 2013. What can ecological science tell us about opportunities for carbon sequestration on arid rangelands in the United States? Global Environmental Change-Human and Policy Dimensions, 23(1): 240-251.

Botta A, Viovy N, Ciais P et al., 2000. A global prognostic scheme of leaf onset using satellite data. Global Change Biology, 6(7): 709-725.

Bradley A V, Gerard F F, Barbier N et al., 2011. Relationships between phenology, radiation and precipitation in the Amazon region. Global Change Biology, 17(6): 2245-2260.

Cao R, Shen M, Zhou J et al., 2018. Modeling vegetation green-up dates across the Tibetan Plateau by including both seasonal and daily temperature and precipitation. Agricultural and Forest Meteorology, 249: 176-186.

Chen M, Melaas E K, Gray J M et al., 2016. A new seasonal-deciduous spring phenology submodel in the Community Land Model 4.5: Impacts on carbon and water cycling under future climate scenarios. Global Change Biology, 22(11): 3675-3688.

Chen X, Li Q, 2009. Relationships between Leymus chinensis phenology and meteorological factors in Inner Mongolia grasslands. Acta Ecologica Sinica, 29(10): 5280-5290. (in Chinese)

Chen X, Wang L, Inouye D, 2017. Delayed response of spring phenology to global warming in subtropics and tropics. Agricultural and Forest Meteorology, 234/235: 222-235.

Chen X Q, Li J, Xu L et al., 2014. Modeling greenup date of dominant grass species in the Inner Mongolian grassland using air temperature and precipitation data. International Journal of Biometeorology, 58(4): $463-471$. 
Chew Y H, Wilczek A M, Williams M et al., 2012. An augmented Arabidopsis phenology model reveals seasonal temperature control of flowering time. New Phytologist, 194(3): 654-665.

Chuine I, 2000. A unified model for budburst of trees. Journal of Theoretical Biology, 207(3): 337-347.

Chuine I, Bonhomme M, Legave J M et al., 2016. Can phenological models predict tree phenology accurately in the future? The unrevealed hurdle of endodormancy break. Global Change Biology, 22(10): 3444-3460.

Cleland E E, Chiariello N R, Loarie S R et al., 2006. Diverse responses of phenology to global changes in a grassland ecosystem. Proceedings of the National Academy of Sciences of the United States of America, 103(37): 13740-13744.

Cong N, Shen M, Piao S et al., 2017. Little change in heat requirement for vegetation green-up on the Tibetan Plateau over the warming period of 1998-2012. Agricultural and Forest Meteorology, 232: 650-658.

Cong N, Wang T, Nan H J et al., 2013. Changes in satellite-derived spring vegetation green-up date and its linkage to climate in China from 1982 to 2010: A multimethod analysis. Global Change Biology, 19(3): 881-891.

Ding M, Li L, Zhang Y et al., 2015. Start of vegetation growing season on the Tibetan Plateau inferred from multiple methods based on GIMMS and SPOT NDVI data. Journal of Geographical Sciences, 25(2): 131-148.

Fu Y, Chen H, Niu H H et al., 2018. Spatial and temporal variation of vegetation phenology and its response to climate changes in Qaidam Basin from 2000 to 2015. Journal of Geographical Sciences, 28(4): 400-414.

Fu Y, Pan X, 2011. Research advances in herbage plant phenology and phenological model of grassland. Chinese Journal of Agrometeorology, 32(3): 319-325. (in Chinese)

Fu Y, Zhang H C, Dong W J et al., 2014a. Comparison of phenology models for predicting the onset of growing season over the Northern Hemisphere. Plos One, 9(10): e109544.

Fu Y H, Piao S, Zhao H et al., 2014b. Unexpected role of winter precipitation in determining heat requirement for spring vegetation green-up at northern middle and high latitudes. Global Change Biology, 20(12): 3743-3755.

Ge Q S, Wang H J, Dai J H, 2014. Simulating changes in the leaf unfolding time of 20 plant species in China over the twenty-first century. International Journal of Biometeorology, 58(4): 473-484.

Hänninen H, 1990. Modelling bud dormancy release in trees from cool and temperate regions. Acta For Fenn, 213: $1-47$.

Hänninen H, Kramer K, Tanino K et al., 2018. Experiments are necessary in process-based tree phenology modelling. Trends in Plant Science, doi: 10.1016/j.tplants.2018.11.006.

He J, Yang K, 2011. China Meteorological Forcing Dataset. Lanzhou: Cold and Arid Regions Science Data Center at Lanzhou. doi: 10.3972/westdc.002.2014.db.

Hunter A F, Lechowicz M J, 1992. Predicting the timing of budburst in temperate trees. Journal of Applied Ecology, 29(3): 597-604.

Jeong S-J, Medvigy D, 2014. Macroscale prediction of autumn leaf coloration throughout the continental United States. Global Ecology and Biogeography, 23(11): 1245-1254.

Jeong S-J, Medvigy D, Shevliakova E et al., 2013. Predicting changes in temperate forest budburst using continental-scale observations and models. Geophysical Research Letters, 40(2): 359-364.

Jin Z, Zhuang Q, He J-S et al., 2013. Phenology shift from 1989 to 2008 on the Tibetan Plateau: An analysis with a process-based soil physical model and remote sensing data. Climatic Change, 119(2): 435-449.

Lebourgeois F, Pierrat J-C, Perez V et al., 2010. Simulating phenological shifts in French temperate forests under two climatic change scenarios and four driving global circulation models. International Journal of Biometeorology, 54(5): 563-581.

Li Q Y, Xu L, Pan X B et al., 2016. Modeling phenological responses of Inner Mongolia grassland species to regional climate change. Environmental Research Letters, doi: 10.1088/1748-9326/11/1/015002.

Li X, Han G, 2013. Response of grass growing season to meteorological change in eastern Inner Mongolia grassland. Chinese Journal of Ecology, 32(4): 987-992.

Linkosalo T, Häkkinen R, Hänninen H, 2006. Models of the spring phenology of boreal and temperate trees: Is there something missing? Tree Physiology, 26(9): 1165-1172.

Liu F S, Chen Y, Shi W J et al., 2017. Influences of agricultural phenology dynamic on land surface biophysical process and climate feedback. Journal of Geographical Sciences, 27(9): 1085-1099. 
Liu H, Tian F, Hu H C et al., 2013. Soil moisture controls on patterns of grass green-up in Inner Mongolia: An index based approach. Hydrology and Earth System Sciences, 17(2): 805-815.

Liu W T, Wang T L, Zhang S et al., 2018. Grazing influences Stipa breviflora seed germination in desert grasslands of the Inner Mongolia Plateau. Peerj, 6: e4447.

Miller-Rushing A J, Hoye T T, Inouye D W et al., 2010. The effects of phenological mismatches on demography. Philosophical Transactions of the Royal Society B-Biological Sciences, 365(1555): 3177-3186.

Munson S M, Long A L, 2017. Climate drives shifts in grass reproductive phenology across the western USA. New Phytologist, 213(4): 1945-1955.

Peters D P C, Herrick J E, Monger H C et al., 2010. Soil-vegetation-climate interactions in arid landscapes: Effects of the North American monsoon on grass recruitment. Journal of Arid Environments, 74(5): 618-623.

Ren S, Chen X, Lang W et al., 2018. Climatic controls of the spatial patterns of vegetation phenology in midlatitude grasslands of the Northern Hemisphere. Journal of Geophysical Research: Biogeosciences, 123(8): 2323-2336.

Richardson A D, Keenan T F, Migliavacca M et al., 2013. Climate change, phenology, and phenological control of vegetation feedbacks to the climate system. Agricultural and Forest Meteorology, 169(3): 156-173.

Ryser P, Sauder W R, 2006. Effects of heavy-metal-contaminated soil on growth, phenology and biomass turnover of Hieracium piloselloides. Environmental Pollution, 140(1): 52-61.

Sun Q, Li B, Yuan Y et al., 2018. A prognostic phenology model for alpine meadows on the Qinghai-Tibetan Plateau. Ecological Indicators, 93: 1089-1100.

Tao Z, Wang H, Liu Y et al., 2017. Phenological response of different vegetation types to temperature and precipitation variations in northern China during 1982-2012. International Journal of Remote Sensing, 38(11): 3236-3252.

Tao Z X, Wang H J, Dai J H et al., 2018. Modeling spatiotemporal variations in leaf coloring date of three tree species across China. Agricultural and Forest Meteorology, 249: 310-318.

Vihera-Aarnio A, Sutinen S, Partanen J et al., 2014. Internal development of vegetative buds of Norway spruce trees in relation to accumulated chilling and forcing temperatures. Tree Physiology, 34(5): 547-556.

Wang S, Wang X, Chen G et al., 2017. Complex responses of spring alpine vegetation phenology to snow cover dynamics over the Tibetan Plateau, China. Science of the Total Environment, 593-594: 449-461.

White M A, Thornton P E, Running S W, 1997. A continental phenology model for monitoring vegetation responses to interannual climatic variability. Global Biogeochemical Cycles, 11(2): 217-234.

Whitecross M A, Witkowski E T F, Archibald S, 2017. Savanna tree-grass interactions: A phenological investigation of green-up in relation to water availability over three seasons. South African Journal of Botany, 108: 29-40.

Wu C Y, Chen J M, 2013. Diverse responses of vegetation production to interannual summer drought in North America. International Journal of Applied Earth Observation and Geoinformation, 21: 1-6.

Xin Q C, 2016. A risk-benefit model to simulate vegetation spring onset in response to multi-decadal climate variability: Theoretical basis and applications from the field to the Northern Hemisphere. Agricultural and Forest Meteorology, 228: 139-163.

Yu F, Price K P, Ellis J et al., 2003. Response of seasonal vegetation development to climatic variations in eastern central Asia. Remote Sensing of Environment, 87(1): 42-54.

Yu R, Schwartz M D, Donnelly A et al., 2016. An observation-based progression modeling approach to spring and autumn deciduous tree phenology. International Journal of Biometeorology, 60(3): 335-349.

Yuan W P, Zhou G S, Wang Y H et al., 2007. Simulating phenological characteristics of two dominant grass species in a semi-arid steppe ecosystem. Ecological Research, 22(5): 784-791.

Zhu W Q, Zheng Z T, Jiang N et al., 2018. A comparative analysis of the spatio-temporal variation in the phenologies of two herbaceous species and associated climatic driving factors on the Tibetan Plateau. Agricultural and Forest Meteorology, 248: 177-184. 